\title{
Escape panels in trawls - a consistent management tool?
}

\author{
Ludvig A. KraG ${ }^{1}$, Bent HerRmANN ${ }^{2}$, Jordan FEeKINGS ${ }^{1}$ and Junita D. KARLSEN ${ }^{1, \text { a }}$ \\ ${ }^{1}$ DTU Aqua, Technical University of Denmark, North Sea Science Park, 9850 Hirtshals, Denmark \\ 2 SINTEF Fisheries and Aquaculture, Fishing Gear Technology, Willemoesvej 2, 9850 Hirtshals, Denmark
}

Received 17 June 2015; Accepted 14 September 2016

\begin{abstract}
Reducing discards of unwanted sizes and species which have a low survival rate is one of the major challenges in fisheries worldwide today. Numerous devices and fishing gears aiming at improving both species and size selectivity have been developed and implemented by various fisheries. Selective gears are often developed in collaboration between scientists and fishers. Part of the development is a controlled scientific test documenting the selectivity effect. In this study, we compared two versions of a mandatory escape panel that were introduced into the mixed species fishery in the Skagerrak in 2013: the version implemented in the legislation (pre-implementation version) and the version the industry was using one year after its implementation, the post-implementation version (post-version). The post-version went through some simple adjustments that resulted in a panel section with a larger vertical distance between the upper panel (escape panel) and the bottom panel compared to the pre-version. Both designs are legal and considered identical. The results of this study showed significantly higher catches (lower selectivity) for the post-version for all five species examined; cod (Gadus morhua), saithe (Pollachius virens), haddock (Melanogrammus aeglefinus), plaice (Pleuronectes platessa) and Norway lobster (Nephrops norvegicus). Thus the modification by fishers of certain gear properties not specified in the legislation can significantly influence the efficiency of an escape panel. We discuss to what extent catch quotas instead of the former landings quotas could provide the economic incentives for fishers to actively use selective gear designs more optimally and thereby play an active role in the management of fisheries.
\end{abstract}

Keywords: Fisheries management / Discard / Technical measures / Legislation / Selectivity / Landing obligation

\section{Introduction}

Technical modifications to fishing gears to reduce bycatch without reducing economic revenue have primarily aimed at reducing the catch of unwanted sizes and species by improving selectivity. The development of such selective devices, e.g. escape panels, grids or new trawl designs (reviewed in Graham 2010) is often based on ideas and experience from the fishing industry, the scientific community or collaborations between the two. The evaluation and documentation of the selective performance of such devices is typically carried out onboard commercial vessels under standardized conditions, e.g. Reeves (1992). Selective devices that reduce bycatch with a minimal effect on economic revenue can either be used on a voluntary basis or be implemented into technical legislation based on the established documentation. However, there is nearly always an economic loss when implementing more selective fishing devices (see Cook 2003). Selective devices that are implemented into technical legislation are normally made mandatory for a specific area, fleet or fishery, irrespective of the diversity of vessel types, vessel sizes or differences in trawl designs already utilized (e.g. Council Regulation No. 850/98).

\footnotetext{
a Corresponding author: lak@aqua.dtu.dk
}

The scientific development and testing of a selective device, and documentation of its effect, typically ends once the device is implemented into legislation unless the industry experiences unforeseen challenges with the device. This is a shortcoming of the scientific testing process and management system. It has previously been noted that selective devices might be rigged and fished in other ways by commercial fishers than during the original scientific experiments (Madsen 2007; Suuronen et al. 2007). If short-term catch losses are too large, gears will be manipulated and rules circumvented (Suuronen et al. 2007). Consequently, when introduced into a fishery, the gear may not perform as expected. If the entire catch was to be counted against the quotas the gear changes made by the industry may be observed to improve the selectivity of the new gear further, as opposed to the current situation where the selective improvements are often negated. Therefore, assessing their effectiveness under commercial settings, post implementation, is necessary.

In 2013 a selective device was introduced into the Norway lobster (Nephrops norvegicus) directed fisheries in the Skagerrak with the aim to reduce the bycatch fishing mortality of cod (Gadus morhua). The selective device consisted of a $270 \mathrm{~mm}$ diamond mesh escape panel installed in the upper panel of a four panel diamond mesh codend. The device aims to avoid 
losses of the main commercial species, Norway lobster, which are observed to roll along the lower part of the trawl (Main and Sangster 1985). The pre-implementation design was developed through a series of trials. To make the implementation as simple as possible the escape panel was integrated into the aft end of a trawl similar to the preferred design used by a majority of the Skagerrak fleet. The scientific and industry intention in the development phase was to make an escape panel that was efficient at removing cod, resulted in minimal losses of Norway lobster, and was simple to make and tailor to fit into gear designs used by the Skagerrak fleet. Prior to its implementation, the escape panel was precisely described in the legal text (BEK No. 1423 of 12/12/2013) specifying the design parameters that are decisive for escape panels: mesh size in the panel, the position of the panel in relation to the cod-line, and the dimensions of the panel (e.g. Graham and Kynoch 2001; Graham et al. 2003; Krag et al. 2008; Fryer et al. 2014).

Initially, most vessels invested in an escape panel section which was similar in construction to the scientifically tested version (henceforth pre-version). As the fishers got acquainted with the new design it became apparent that a series of small design changes were gradually made in the rigging and construction of the panel section. It was apparent that the commercial mounting of the escape panel in the trawl and the aft part of the trawl designs used in this fishery had changed in response to the mandatory use of the escape panel (resulting in the post-version). All observed changes were within the legal bounds of the legislation specifying the mandatory escape window. The post-version was placed further forward in the trawl and used no extension piece. It was the rigging of the escape panel section to the trawl body that differed between the two designs, where the distance between the upper and lower netting in the panel section was increased in the post-version compared to the pre-version. This adaptation was made as the fishers feared that the Norway lobster would come in contact with the large meshes in the escape panel and escape. Such construction changes may however affect to what extent fishes get in contact with the escape panel, thereby reducing the intended selectivity of the panel.

In this study, we estimated and compared the size selectivity of the pre-version that the legislation was based on, with the post-version, which a majority of the industry, according to local net makers, was using one year after the legal implementation. Both designs use identical codends and escape panel sections which are specified in the legislation. They are however mounted with different joining rates to the trawl-body and the pre-version uses a $3 \mathrm{~m}$ long extension piece whereas there is no extension piece in the post-version. Further, we discuss the applicability of selective devices which are dependent on fish contacting the selective device and actively escaping through it, and factors that can influence this contact.

\section{Material and methods}

\subsection{Experimental setups}

Two identical codend sections, with a total stretched length of $7.4 \mathrm{~m}$ were constructed out of $90 \mathrm{~mm}$ (nominal) diamond mesh made from double $4 \mathrm{~mm}$ PE twine (Fig. 1). Both codends were four panel constructions where each panel had 24 open meshes in all four panels and 4 meshes in each of the four selvedges. The $270 \mathrm{~mm}$ (nominal) diamond mesh escape panel (henceforth escape panel) was mounted in the square section of the top panel and joined to the $90 \mathrm{~mm}$ codend meshes with the ratio 1:3 in both codends. The escape panel was 8 meshes wide and 12 meshes long. The escape panels were inserted 4-7 m from the cod-line, stretched measure. The design, development and initial scientific tests of the mandatory escape panel are described Krag et al. (2013).

The only difference between the two codend sections was that the pre-version was joined to the trawl body with a joining rate of 1:1 (96 meshes to 96 meshes) whereas the postversion had a joining rate of 1.4:1 (130 meshes to 96 meshes). A section, 34 meshes long in the last tapered section in the trawl body was therefore removed in the post-version to obtain the 1.4:1 joining rate. In addition, there was a $3 \mathrm{~m}$ long untapered extension piece, having 96 open meshes in the circumference ahead of the escape panel section in the pre-version, as used by most vessels before the escape panel was implemented. These differences in joining rate to the trawl body and whether an extension piece was used or not resulted in a smaller vertical distance between the lower and upper panel in the pre-version compared to the post-version. Flume tank measurements of codends of similar designs as in the pre- and post-version were conducted prior the current experiment to examine the effect of different joining rates and the use of an extension piece. These measurements, made on full scale codend sections, indicated that the height in the escape panel section varied from about $20 \mathrm{~cm}$ in a design similar to the preversion to about $50 \mathrm{~cm}$ in a design similar to the post-version (unpublished data). We expect a similar difference for the escape panel height between the two designs in the current experiment but have no direct measurements to quantify the exact difference during fishing. The purpose of testing the two designs in parallel was to quantify the effect that the vertical opening in the panel sections has on the selectivity efficiency of the escape panel.

The covered codend method (Wileman et al. 1996) was used to collect individuals which escaped through either the escape panel or the codend meshes. The last $10 \mathrm{~m}$ of each trawl were fitted with a small mesh cover made from $40 \mathrm{~mm}$ (nominal) Dynema netting with a twine thickness of $1.8 \mathrm{~mm}$. The two covers used were identical and their geometry was obtained using kites and weights following the design described in Madsen et al. (2001). The covers had a total length of $24.9 \mathrm{~m}$ with the cylindrical, most open section between the kites being $8 \mathrm{~m}$ long. Forward of the cylindrical section was a $6 \mathrm{~m}$ conical section for attaching to the body of the trawl. Both covers were attached to the trawl body where the circumference was 140 meshes. The large covers ensured that the two different lengths of the pre- and post-version of the escape panel both could go into the covers without the risk of masking either the codend or the escape panel.

\subsection{Experimental fishing}

The experimental fishing was conducted in the North Sea and Western Skagerrak onboard the commercial twin-trawler 

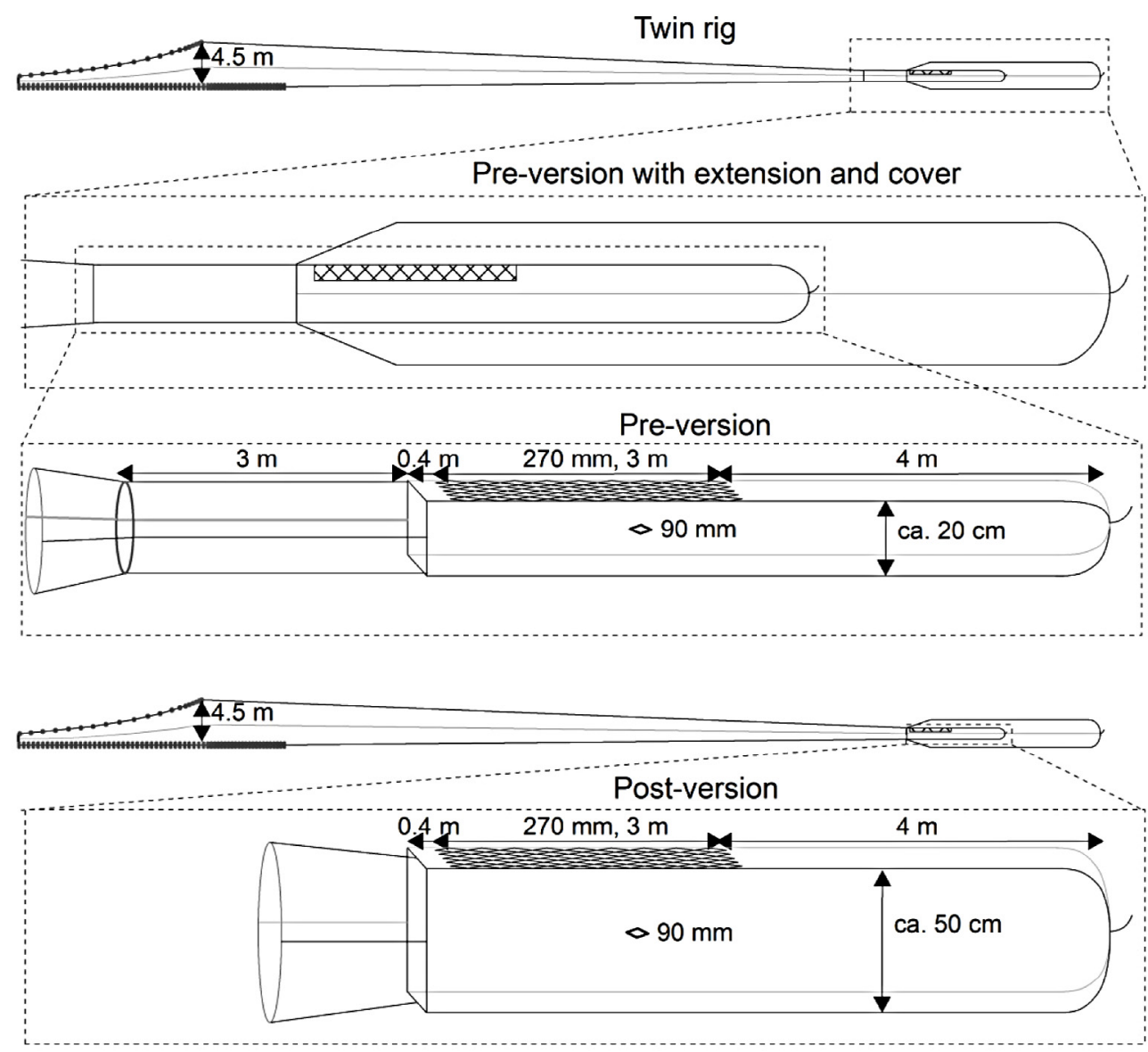

Fig. 1. Design of pre- and post-versions tested simultaneously using a twin-trawl setup. The $7.4 \mathrm{~m}$ long codend sections in the two designs were identical but mounted differently to the trawl body (see text for further details). The conical section in front of both codends represents the trawl body. Identical codend covers were used to collect escapees.

HM 128 Borkumrif (28 m and $728 \mathrm{~kW}$ ). The vessels' combined fish and Norway lobster trawls were used and towed simultaneously, in parallel using a three warp towing rig. All tows were conducted with the aim of reflecting typical commercial fishing practices. The trawl had a circumference of 580 meshes in the fishing circle with a nominal mesh size of $120 \mathrm{~mm}$. The trawl was constructed with an upper and a lower panel and two wedges, one in each side. The ground gear consisted of $36 \mathrm{~cm}$ rockhopper discs in the center section and $30 \mathrm{~cm}$ rockhopper discs in the rest of the ground gear. The towing rig was spread with two $244 \mathrm{~cm}$ Thyborøn Type 11 trawl doors and a $1400 \mathrm{~kg}$ Thyborøn roller clump. Single sweeps $(174 \mathrm{~m})$ were used between the trawl doors and the wings of the trawl. Geometry was monitored for both trawls together as total door spread and individually as double spread measurements using Scanmar gear surveillance sensors. The sensor information was recorded every 10-15 min; average spread and standard deviation were calculated.

For each haul the entire catch was sorted by species, total length of commercial fishes was measured to the nearest centimeter below, while for Norway lobster carapace length (in millimeters) was measured. In the subsequent selectivity analysis, $0.5 \mathrm{~cm}$ was added for fishes and $0.5 \mathrm{~mm}$ for Norway lobster following e.g. Krag et al. (2014). No subsampling was made except for one haul for both haddock and Norway lobster due to large catches. In these hauls, a minimum of 350 individuals were measured in each codend and cover. Hauls with more than 10 individuals of the species were included in the analysis following the procedure outlined in Krag et al. (2014).

\section{Estimation of size selectivity in the pre- and post-version}

The data were analysed by species separately for the preand post-version using the method described below.

To estimate the size selection in the codend (i.e., lengthdependent retention probability) a binomial variable was created by coding fish retained by the codend cover as 0 and those by the codend itself as 1 . The probability of a fish of length $l$ ending up in the codend in haul $j$ is expressed by the function $r_{j}(l)$. In this study, we were interested in the lengthdependent values of $r_{j}(l)$ averaged over all hauls, because this provided information about the average consequences for the size selection process of applying the two gear designs in the fishery. Estimation of the average size selection over hauls involved pooling data from the different hauls for respectively 
the pre- and post-versions, and since we used a parametric model we write $\bar{r}(\boldsymbol{l v})$, where $\boldsymbol{v}$ is the vector of model parameters. For modelling the size selection in the combined selection system, consisting of the escape panel and the diamond mesh codend, we used a dual model to account for the fact that not necessary all fish came into contact with the escape panel during their drift towards the aft of the codend:

$$
\begin{aligned}
\bar{r}(l, v)= & \left(1.0-C_{\text {panel }}\left(1.0-\operatorname{logit}\left(l, L 50_{\text {panel }}, S R_{\text {panel }}\right)\right)\right) \\
& \times \operatorname{logit}\left(l, L 50_{\text {codend }}, S R_{\text {codend }}\right)
\end{aligned}
$$

where

$$
\operatorname{logit}(l, L 50, S R)=\frac{\exp \left(\frac{\ln (9)}{S R}(l-L 50)\right)}{1+\exp \left(\frac{\ln (9)}{S R}(l-L 50)\right)} .
$$

Equation (2) is the standard logit size selection model applied to describe size selection in nets of towed fishing gears (Wileman et al. 1996).

The model (1) accounts for the independent size selection processes by the two selection devices (escape panel and diamond mesh part of the codend). For the escape panel, the model accounts for that not necessary all fish make contact with it. For the fish that make contact, we assume a logit size selection model. Further, fishes that did not escape through the escape panel are subjected to size selection in the diamond mesh part of the codend. This process is modelled by a second logit size selection model. The paramter $C_{\text {panel }}$ can be interpreted as the probability for a fish to make contact with the escape panel during its drift towards the aft end of the codend; $C_{\text {panel }}$ takes values between 0.0 and 1.0. L50 panel and $S R_{\text {panel }}$ (L50: length at which $50 \%$ of the fishes are retained; SR: selection range, $L_{75}-L_{25}$ ) are the selection parameters in the logit model that describe the size selection of the escape panel for individuals that make contact with it. $L 50_{\text {codend }}$ and $S R_{\text {codend }}$ are the corresponding size selection parameters in the logit size selection model for the aft part of the diamond-mesh codend. Zuur et al. (2001) previously described and applied a model identical to model (1) for the combined size selectivity of a square-mesh panel preceded by a diamond mesh codend. O’Neill et al. (2006) applied such a model for a similar selection system.

The overall selectivity parameters for the combined system, consisting of the escape panel and the remaining part of the codend made of diamond mesh netting ( $L 50_{\text {combined }}$ and $S R_{\text {combined }}$ ) were estimated using a numerical method because analytical expressions could not be derived. Conditional on the estimated values for $C_{\text {panel }}, L 50_{\text {panel }}, S R_{\text {panel }}, L 50_{\text {codend }}$, and $S R_{\text {codend }}$ the method numerically searched for the length $l$ for which $\bar{r}(l)=0.5$; this length is $L 50_{\text {combined }}$ according to the definition in Wileman et al. (1996). $S R_{\text {combined }}\left(=L 75_{\text {combined }}-\right.$ $L 25_{\text {combined }}$ ) was estimated using the same approach.

The values for the five parameters in (1) were estimated by Maximum Likelihood. For this function (3) was minimized, which is equivalent to maximizing the likelihood for the observed experimental data:

$$
-\sum_{j} \sum_{l}\left\{\frac{n C_{j l}}{q C_{j}} \ln (\bar{r}(l, \boldsymbol{v}))+\frac{n C C_{j l}}{q C C_{j}} \ln (1.0-\bar{r}(l, \boldsymbol{v}))\right\}
$$

where the summations are over hauls $j$ and length classes $l$, and $q C_{j}$ and $q C C_{j}$ are the length-independent subsampling rates for haul $j$ for the codend and codend cover, respectively. $n C_{j l}$ and $n C C_{j l}$ are the number of fish of length $l$ observed in the codend and cover respectively in haul $j$.

Evaluation of the ability of the model (1) to describe the experimental data sufficiently well was based on calculating the probability ( $p$-value) to obtain at least as big a discrepancy between the fitted model and the observed experimental data if the model was correct. For the fitted model to be suitable to describe the size selection data, this $p$-value should be larger than 0.05 (Wileman et al. 1996). However a lower $p$-value could both be due to the model's inability to describe the length-based structure of the data or due to overdispersion in the experimental data, i.e. more observed variability when expected for the binomial distribution. In such cases, residual plots were used to discriminate between overdispersion and structural problems in the model's ability to describe the experimental data (Wileman et al. 1996). To account for both within- and between-haul variation in selectivity (Fryer 1991) when estimating uncertainty for the average size selection, we applied the software tool SELNET (Herrmann et al. 2012), and utilized the double bootstrap method. For each case analyzed (specific species for specific codends), 1000 non-parametric bootstrap samples were created to estimate the Efron 95 percentile confidence limits for both the selection parameters and curve (Herrmann et al. 2012). This double bootstrap method is similar to the one described in Millar (1993) and to the one applied in Sistiaga et al. (2010). To account for between-haul variation, an outer bootstrap resample with replacement from all hauls was carried out. Within each resampled haul, the data for each length class was bootstrapped in an inner bootstrap with replacement to account for within-haul variation. The inner resampling of the data in each length class was performed prior to the raising of the data, to avoid underestimating of the within-haul variation in case of subsampling.

To determine whether there were any significant differences between the size selectivity for pre- and post-versions, the confidence limits around the two selection curves were plotted and inspected for overlap. The escape panel sections of the two versions were identical but differences in the rigging of these sections led to differences in the distance between the lower netting and the escape panel in the panel section. Any differences in the estimated retention probabilities were therefore likely to be mainly the result of differences in contact probabilities with the escape panels.

\section{Results}

\subsection{Operational conditions}

A total of 12 hauls were conducted on commercial fishing grounds. The total catch of cod, saithe, haddock, plaice and Norway lobster in both codend and cover is given for each haul for the pre- and post-version in Table 1. Towing speed was 2.8 knots which is standard in the Norway lobster directed fishery. Additional operational conditions for each haul are provided in Table 2. Table 3 lists the measurements of the mesh sizes in the codends, escape panels, covers and in the extension piece used. All measurements were conducted on dry netting 

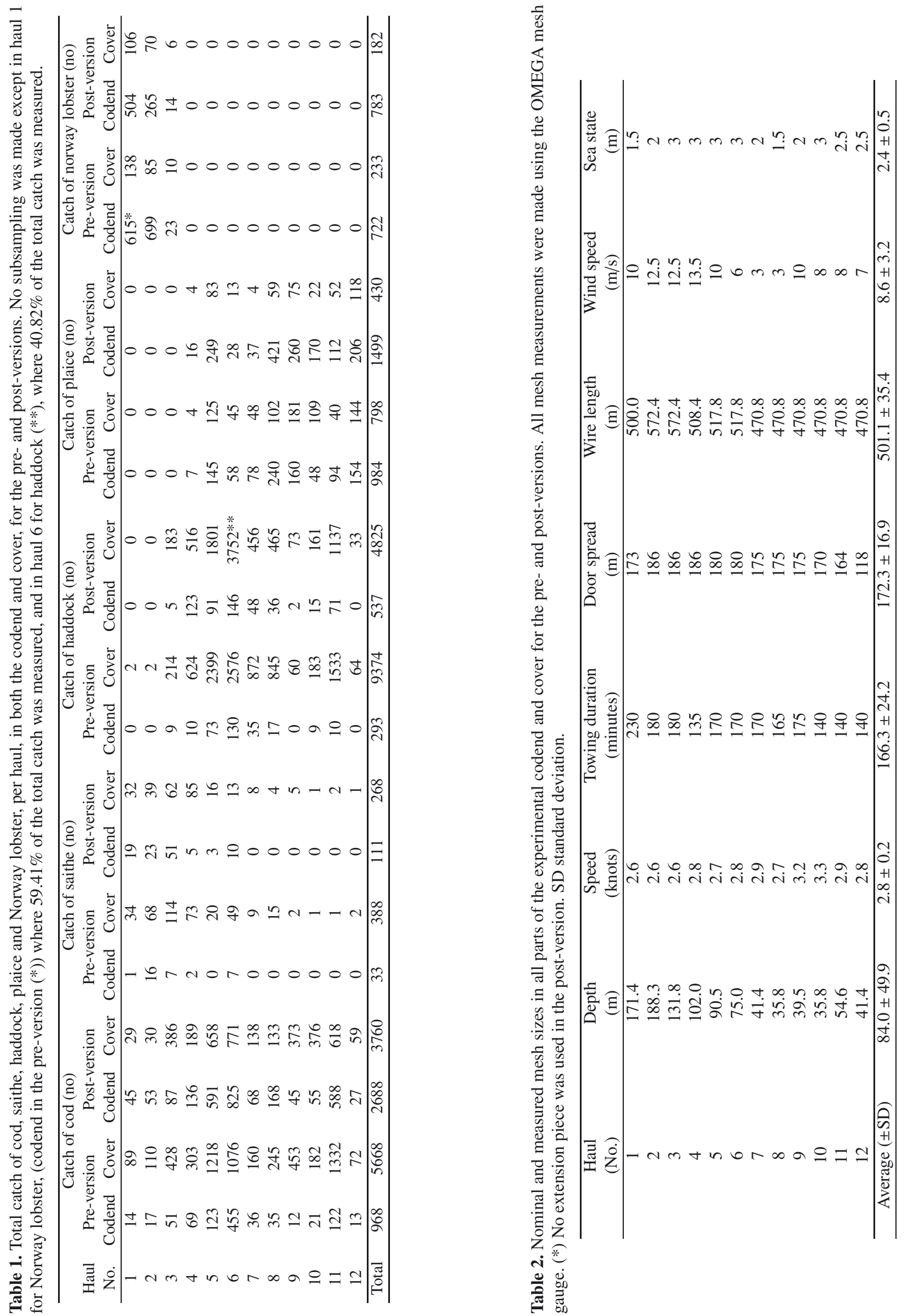
Table 3. Average operational conditions for each haul. SD standard deviation.

\begin{tabular}{lccc}
\hline Gear section & $\begin{array}{c}\text { Nominal } \\
\text { Meshes } \\
(\mathrm{mm})\end{array}$ & $\begin{array}{c}\text { Pre-version } \\
\text { Measured }(\mathrm{mm}) \\
\text { mean } \pm \mathrm{sd}\end{array}$ & $\begin{array}{c}\text { Post-version } \\
\text { Measured }(\mathrm{mm}) \\
\text { mean } \pm \mathrm{sd}\end{array}$ \\
\hline Extension & 90 & $91.1 \pm 1.49$ & $*$ \\
Escape panel & 270 & $280.8 \pm 2.41$ & $280.6 \pm 2.82$ \\
Panel section & 90 & $91.9 \pm 1.40$ & $89.9 \pm 1.59$ \\
Codend & 90 & $95.1 \pm 2.37$ & $95.1 \pm 2.72$ \\
Cover & 40 & $44.0 \pm 1.35$ & $43.9 \pm 1.47$ \\
\hline
\end{tabular}

after the sea trails. Catch data for five economically important species were included in the analysis; cod (12 hauls), haddock (10 hauls), plaice (9 hauls), saithe (7 hauls) and Norway lobster (3 hauls).

\subsection{Estimated selectivity}

Figure 2 illustrates the mean selectivity curves for both versions with $95 \%$ confidence limits. The model captured the main patterns in the data relatively well without systematic deviations between the fitted model and the experimental data (Fig. 2). The fitted selectivity curves were not sigmoidal but more flat, indicating that selectivity occurred in both the escape panel and the codend meshes. There was a significant difference in the selectivity between the two designs for the five species analyzed since for some length classes where there was no overlap between confidence limits for the two size selection curves (Fig. 3). This difference was length dependent and varied considerably between species. The largest effect was observed for cod where the pre-version was significantly more selective for individuals in the length range $25-75 \mathrm{~cm}$. The majority of individuals caught were within this size range (Fig. 2). For saithe, the retention probability curves were lower than for cod. As for cod, there was also a large significant difference between the two designs' retention probabilities for saithe. The size selectivity for saithe was significantly lower in the postversion compared to the pre-version in the length range $43-$ $82 \mathrm{~cm}$. For haddock, there was a significant difference in the length range $33-38 \mathrm{~cm}$. However, the difference in selectivity between the two designs for haddock was not as pronounced as for cod and saithe. The confidence limits for haddock were wide and overlapped for larger individuals as relative few of those were caught. The retention probabilities for plaice were in general higher than for the three gadoid species described above, due to lower contact probabilities with the escape panel. The pre-version was significantly more selective in the length range $24-38 \mathrm{~cm}$. The retention probability for Norway lobster was generally high for both designs. The estimated retention probability curves were relatively similar for the two designs in the length range of the individuals caught (Fig. 2) but were significantly different in the length range $37-42 \mathrm{~mm}$ carapace length (Fig. 3). The retention probability of Norway lobster, compared to the fish species, was less sensitive to differences in the geometry in the escape panel section.

Separate selectivity parameters ( $L 50$ and $S R$ ) were estimated for the escape panel, for the codend and for the combined effect for both the pre- and post-versions (Table 4). L50 for the combined selectivity was estimated to be higher for all species in the pre-version compared to the post-version
(Table 4). However, estimated values were not significantly different between the two versions as confidence intervals overlapped (Table 4). Estimated individual selectivity parameter values have to be interpreted with caution as these parameters were estimated for the escapees combined, as there was no separate sampling of panel escapees and codend escapees. This lead to high uncertainty in estimated values for individual parameters (Table 4; Sistiaga et al. 2010). The large mesh size used in the escape panel $(270 \mathrm{~mm})$ will allow all individuals in the size ranges caught to escape through the escape panel meshes (see experimental observed retention lengths in Fig. 2). Therefore, the observed retention probabilities indicated the length based contact, as those that were retained had not successfully been in contact with the escape panel.

Model fit statistics are shown in Table 5. For haddock, the $p$-values were below 0.05 but there were no systematic patterns in the deviations between the modelled selectivity curve and the experimental data points (not shown). Therefore, we are confident in applying model (1) also for haddock.

\section{Discussion}

In this study, we compared the size selectivity of two legal versions of the same selective trawl. The only difference between the two trawls was in the height of the gear section with the escape panel. The process of commercial uptake of the escape panel involved a few relative simple modifications which resulted in a significant reduction in selectivity for species specific length intervals for all five species examined. Furthermore, the results showed that the effect of selective devices, such as escape panels, can be sensitive to changes in rigging of the gear and not just the rigging of the selective escape panel. The overall geometry in the gear section where the selective device is mounted was observed to affect the device's selective performance. Only the part of the gear in which the escape panel was inserted is specified in the legislation. This study showed that modifications made to other sections of the gear can significantly change the selectivity of such devices.

The objective of the commercial adaptation of the escape panel section was to prevent unintended loss of marketable sized Norway lobster, which is economically the most important species in this fishery. The comparison between the two designs showed that there was little difference between the average retention probabilities for Norway lobster, however, significant for a small length range around $40 \mathrm{~mm}$ carapace length. Altering the selectivity of the gear to minimizing the small loss of Norway lobster observed in the post-version considerably reduced the selectivity for cod, saithe, haddock and plaice when compared to the selectivity in the pre-version.

It could be argued that the observed differences in selectivity could be prevented by a more comprehensive legal text preventing all modifications that lead to a significant reduction in the selectivity. This requires that we know the effect of all possible modifications which is not the case. Further, there is a simple logic in keeping legal texts simple when describing the influential design parameters in a given design; they should be clear for the parties who are going to work with the new gear (fishers and net-makers) and for the fisheries inspectors to be able to enforce it. The relevant legal text, specified in BEK No. 1423 of 12/12/2013 

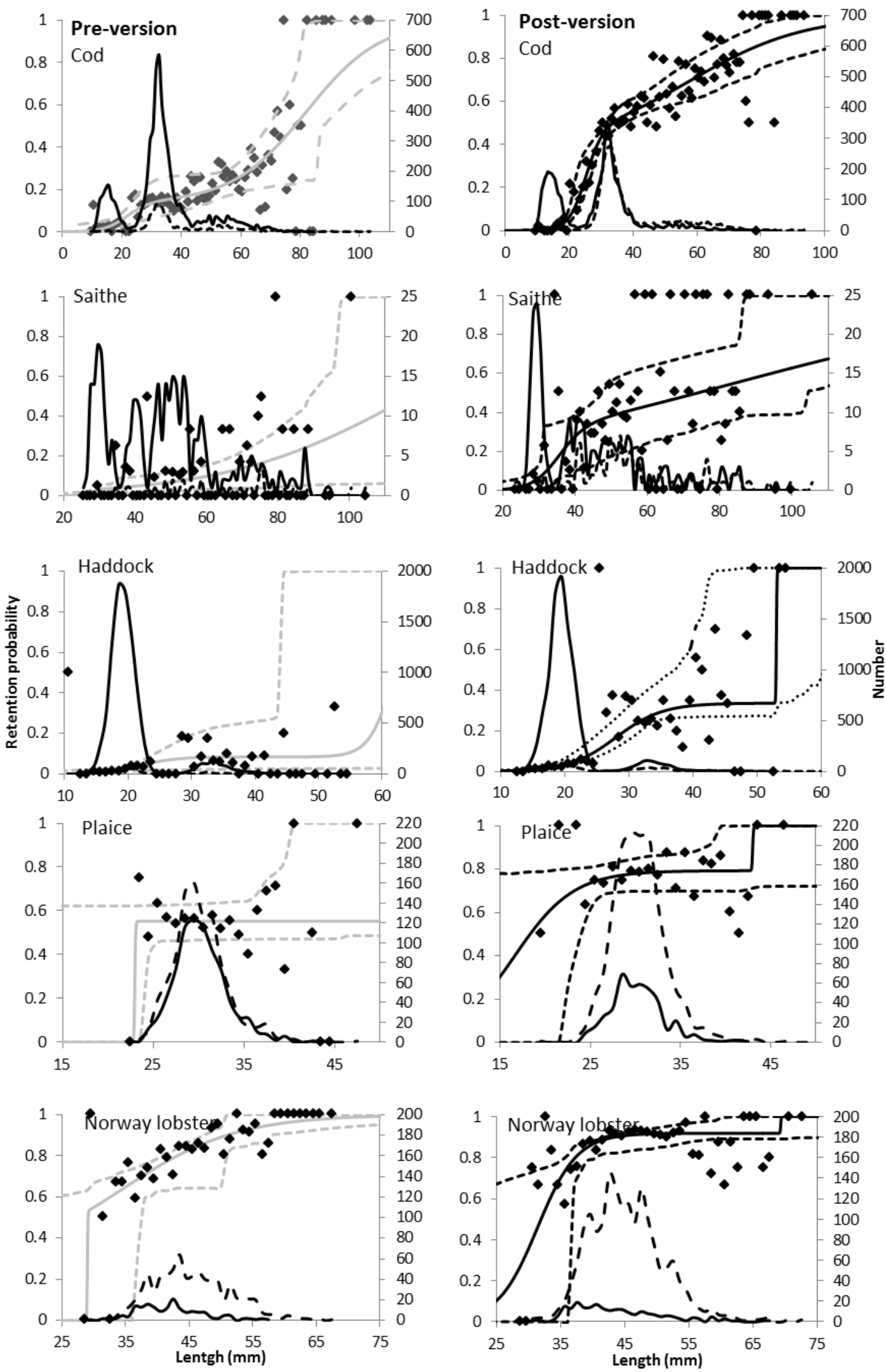

Fig. 2. Estimated average selection curve (solid curve) with $95 \%$ confidence limits (broken lines). Black diamonds represent the experimental retention rate at length. The solid black line represents the individuals retained in the cover, whereas the broken black line represents the individuals caught in the codend. 

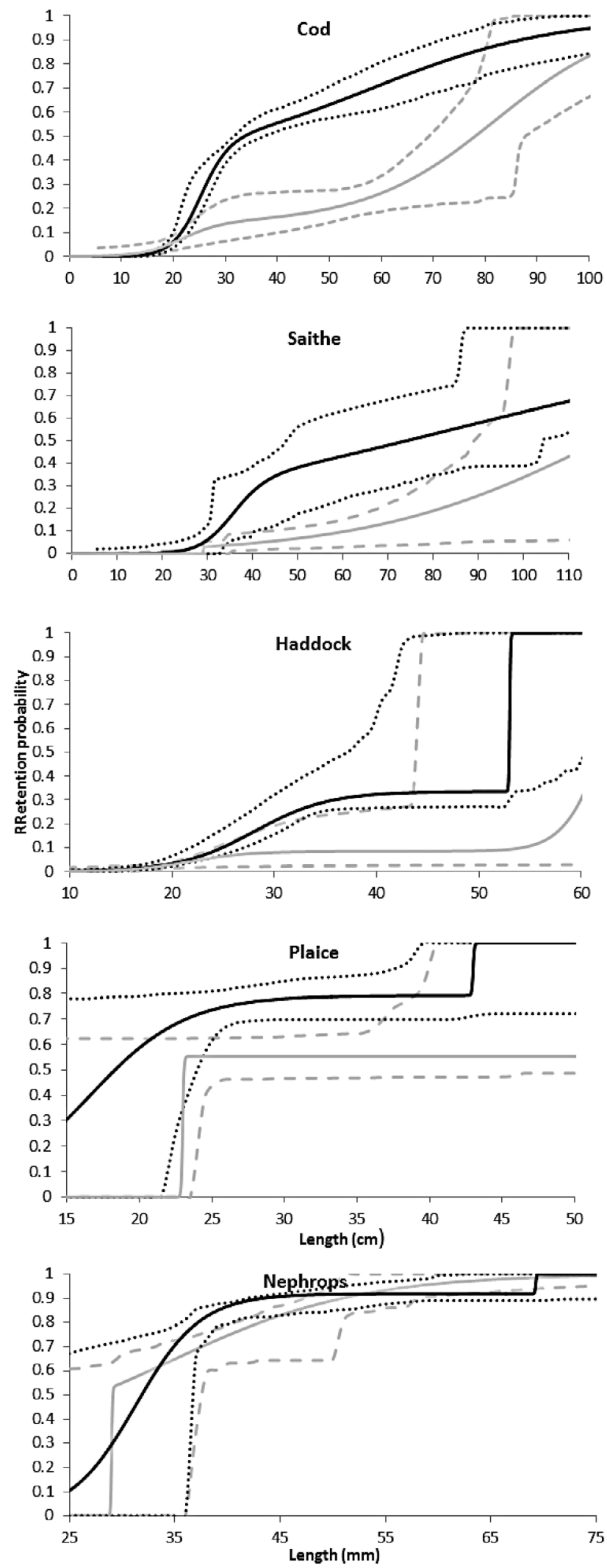

Fig. 3. Estimated average selection curve for the pre-version (solid grey line) with $95 \%$ confidence limits (grey broken lines) and the post-version (solid black line) with $95 \%$ confidence limits (broken lines). Length intervals without overlap between the two designs indicate significant differences.

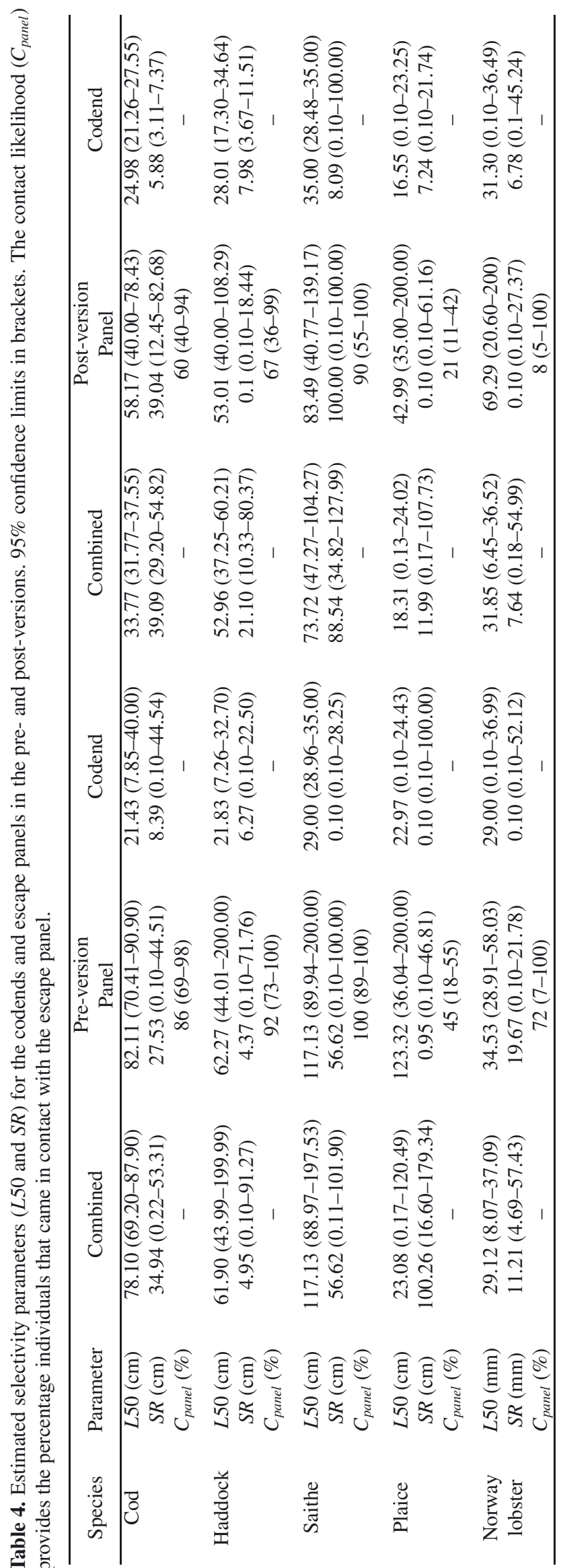


Table 5. Model fit statistics by species and design. DOF degrees of freedom.

\begin{tabular}{lcccccc}
\hline Species & $p$-value & $\begin{array}{c}\text { Post-version } \\
\text { Deviance }\end{array}$ & DOF & $p$-value & $\begin{array}{c}\text { Pre-version } \\
\text { Deviance }\end{array}$ & DOF \\
\hline Cod & 0.0223 & 101.56 & 75 & 0.4084 & 79.23 & 77 \\
Haddock & 0.0046 & 63.27 & 37 & 0.0007 & 71.87 & 38 \\
Saithe & 0.1439 & 74.96 & 63 & 0.4736 & 62.07 & 62 \\
Plaice & 0.2062 & 24.88 & 20 & 0.1834 & 23.19 & 18 \\
Norway lobster & 0.2263 & 43.11 & 37 & 0.7729 & 26.69 & 33 \\
\hline
\end{tabular}

(www.faolex.fao.org/docs) is specific in describing the mesh size in the escape panel, the sizes of the panel, the joining ration between panel meshes and trawl netting, the position of the escape panel relative to the cod-line, and the codend construction, which according to the literature are the only governing parameters in terms of efficiency of escape panels (e.g. Graham and Kynoch 2001; Graham et al. 2003; Krag et al. 2008; Herrmann et al. 2015). In this study, the above mentioned design parameters were identical; however, the selectivity was significantly different for all species analysed. This demonstrates that the selectivity of escape panels can be significantly influenced by additional design parameters that affect the geometry in the panel section. Such changes, which can lead to changes in the overall geometry, can be obtained in several ways and are therefore difficult to prevent by a more detailed legal text. This new knowledge should be taken into consideration when testing and implementing new selective devices whose selectivity is dependent on fish contacting the selective device, e.g. an escape panel. The observed sensitivity in fish contacting the selective device indicates that if such selective designs are made mandatory across a diverse fleet, different selective performances may be observed simply due to the difference in the gears used (Tschernij and Holst 1999). The escape panels used in the current study were positioned in the aft end of the trawl where most gears are relatively identical, but variations in the number of meshes in the circumference and the shape of the trawl which the panel section is joined to may cause intra-fleet variations in selectivity.

This experiment demonstrated that it is not sufficient to install a selective device which requires individuals to actively attempt escape; individuals also need to be presented with the possibility of escaping through the device. Similar conclusions have previously been demonstrated in fish behavioural experiments (Glass and Wardle 1995) and theoretical studies on selective devices (Krag et al. 2011). One such mechanism that could stimulate fish to contact an escape panel is panic behaviour (Krag et al. 2009). In the design with a smaller vertical height in the panel section (pre-version) the probability of fish contacting the surrounding netting is expected to be higher than what would be expected in the post-version. Such an environment will probably make fishes modify their behaviour, resulting in a behaviour which increases their contact with the surrounding meshes and the escape panel.

The successful use of technical measures appears to depend largely on their acceptance by industry (Suuronen and Sarda 2007). Monitoring of a device's effectiveness post implementation is therefore important (Cox et al. 2007; Feekings et al. 2013). Fishers in general do not want to catch large numbers of bycatch species whose stocks, and subsequently quotas, are depleted. Under a landings quota system, where only the landings are counted against the quotas, such catch has no economic value and is discarded. Therefore, under such a management system, modifications which reduce the intended selectivity can therefore be made at no monetary cost to the fisherman. Based on the clear lack of incentives or economical drivers for fishers to fine-tune their gear towards the intended selectivity, it can be argued that the management system is largely responsible for the fishers modifying the selectivity of their gears. Cox et al. (2007) reviewed three different case studies of pre- and post-implementation devices to reduce the bycatch of marine mammals, seabirds and turtles. All cases pointed out the importance of incentives, especially economic incentives. Under a landings quota the objectives of the management system and those of the fishers are not aligned. Managers aim to reduce the bycatch and discards of unwanted species and sizes while fishers aim to optimize/sustain their income. Under a management system where the entire catch is counted against the quota, as is gradually introduced into all EU fisheries since 2015, the objectives of the management system and those of the fishers are more aligned. The objective of the management system remains the same; reduce unwanted catches, whereas the objective of the fishers is now also to reduce unwanted catches as these can be considered to have a monetary value as they are counted as part of the quota. A discard ban is currently implemented in Alaska, British Columbia, New Zeeland, the Faroe Islands, Norway and Iceland (Condie et al. 2014). Experience from these countries highlights that a policy of mandatory landings can result in a reduction of discards, but relies upon a high level of surveillance or economic incentives to encourage fishers to land more of their catch (Condie et al. 2014). Moving to target-based management is a paradigm shift with appealing advantages in theory, but serious implementation hurdles in practice (Condie et al. 2014).

This study also highlights the importance of a good scientific understanding of which mechanisms affect the performance of selective devices, since this would help ensuring that pre-implementation testing is conducted in a way which would reflect how the post-implementation design would work in the fishery when fishers rig it or change the rigging of it. The commercial adaptation of the escape panel tested herein clearly demonstrates that fishers, through their practical knowledge, are able to fine-tune selective devices so they work optimally in an economic sense under the given conditions. This could indicated that technical regulations may become an important and more efficient regulatory tools for the EU fisherman 
in the future as the economical drivers for minimizing unwanted by-catch are present in the landing obligation system.

Acknowledgements. This study was conducted with financial support from the Ministry of Food, Agriculture and Fisheries of Denmark and the EU H2020 DiscardLess Project. Thanks are due to Søren Grønby Larsen and Jan Pedersen (DTU Aqua) and skipper Flemming Nielsen and the crew on board the commercial trawler HM 129 Borkumrif, and to Henrik Lund and Jan Hansen from the Danish Fishermen's Association.

\section{References}

Condie H.M., Grant A., Catchpole T.L., 2014, Does banning discards in an otter trawl fishery create incentives for more selective fishing? Fish. Res. 148, 137-146.

Cook R., 2003, The magnitude and impact of by-catch mortality by fishing gear. In: Sinclair M., Valdimarsson G. (Eds.), Responsible Fisheries in the Marine Ecosystem, Oxford, pp. 219-233.

Council Regulation No. 850/98. Council Regulation (EC) No. 850/98 of 30 March 1998 for the conservation of fishery resources through technical measures for the protection of juveniles of marine organisms. Official Journal of the European Communities, p. 36.

Cox T.M., Lewison R.L., Zydelis R., Crowder L.B., Safina C., Read A.J., 2007, Comparing Effectiveness of Experimental and Implemented Bycatch Reduction Measures: the Ideal and the Real. Concerv. Biol. 21, 1155-1164.

Feekings J., Lewy P., Madsen N., 2013, The effect of regulation changes and influential factors on Atlantic cod discards in the Baltic Sea demersal trawl fishery. Can. J. Fish. Aquat. Sci. 70, 534-542.

Fryer R., 1991, A model of the between-haul variation in selectivity. ICES J. Mar. Sci. 48, 281-290.

Fryer R.J., O’Neill F.G., Edridge, A., 2014, A meta-analysis of haddock size-selection data. FISH FISH. DOI: 10.1111/faf. 12107. 12, 1-17.

Glass C.W., Wardle C.S., 1995, Studies on the use of visual stimuli to control fish escape from codends. II. The effect of a black tunnel on the reaction behaviour of fish in otter trawl Codends. Fish. Res. 23, 165-174.

Graham N., 2010, Technical measures to reduce bycatch and discard in trawl fisheries. In: He P. (Ed.), Behavior of marine fishes capture processes and conservation challenges, pp. 239-264.

Graham N., Kynoch R.J., 2001, Square mesh panels in demersal trawls: some data on haddock selectivity in relation to mesh size and position. Fish. Res. 49, 207-218.

Graham N., Kynoch R.J., Fryer R.J., 2003, Square mesh panels in demersal trawls: further data on haddock and whiting selectivity in relation to panel position. Fish. Res. 62, 361-375.

Herrmann B., Sistiaga M., Nielsen K.N., Larsen R.B., 2012, Understanding the size selectivity of redfish (Sebastes spp.) in North Atlantic trawl codends. JNAFS., 44, 1-13.
Herrmann B., Wienbeck H., Karlsen J.D., Stepputtis D., Dahm E., Moderhak W., 2015, Understanding the release efficiency of Atlantic cod (Gadus morhua) from trawls with a square mesh panel: effects of panel area, panel position, and stimulation of escape response. ICES J. Mar. Sci. 72, 686-696.

Krag L.A., Herrmann B., Karlsen J.D., 2014, Inferring escape behaviour in trawls based on catch comparison data: Model development and evaluation based on data from Skagerrak, Denmark. PLoS One, Vol. 9, Issue, 2, e88819,

Krag L.A., Frandsen R.P., Madsen N., 2008, Evaluation of a simple means to reduce discard in the Kattegat-Skagerrak Nephrops (Nephrops norvegicus) fishery: commercial testing of different codends and square-mesh panels. Fish. Res. 9, 175-186.

Krag L.A., Madsen N., Karlsen J.D., 2009, A study of fish behaviour in the extension of a demersal trawl using a multi-compartment separator frame and SIT camera system. Fish. Res. 98, 62-66

Krag L.A., Herrmann B., Madsen N., Frandsen R.P., 2011, Size selection of haddock (Melanogrammus aeglefinus) in square mesh codends: A study based on assessment of decisive morphology for mesh penetration. Fish. Res. 110, 225-235.

Krag L.A., Storr-Paulsen M., Vinter M., Herrmann B., Madsen N., Frandsen R.P., Karlsen J.D., 2013, Dokumentation af selektiv effekt af SELTRA 180, p. 48. (In danish).

Madsen N., 2007, Selectivity of fishing gears used in the Baltic Sea cod fishery. Rev. Fish. Biol. Fisher. 17, 517-544.

Madsen N., Hansen K.E., Moth-Poulsen T., 2001, The kite cover: a new concept for covered codend selectivity studies. Fish. Res. 49, 219-226.

Main J., Sangster G.I., 1985, The behaviour of Norway lobster (Nephrops norvegicus L.) during trawling. Scottish Fisheries Research Report 34, 23 p.

Millar R.B., 1993, Incorporation of between-haul variation using bootstrapping and nonparametric estimation of selection curves. Fish. Bull. 91, 564-572.

O’Neill F.G., Kynoch R.J., Fryer R.J., 2006, Square mesh panel in North Sea demersal trawls: separate estimates of panel and codend selectivity. Fish. Res. 78, 333-341.

Reeves S.A., Armstrong D.W., Fryer R.J., 1992, The effect of mesh size, cod-end extension length and cod-end diameter on the selectivity of Scottish trawl and seines. ICES J. Mar. Sci. 49, 279-288.

Sistiaga M., Herrmann B., Grimaldo E., Larsen R.B., 2010, Assessment of dual selection in grid based selectivity systems. Fish. Res. 105, 187-199.

Suuronen P., Sarda F., 2007, The role of technical measures in European fisheries management and how to make them work better. ICES J. Mar. Sci. 64, 751-756.

Suuronen P., Tschernij V., Jounela P., Valentinsson D., Larsson P.O., 2007, Factors affecting rule compliance with mesh size regulations in the Baltic cod trawl fishery. ICES J. Mar. Sci. 64, 1603 1606.

Wileman D., Ferro R.S.T., Fonteyne R., Millar R.B., 1996, Manual of Methods of Measuring the Selectivity of Towed Fishing Gears, ICES Coop. Res. Rep., No. 215, 126 p.

Zuur G., Fryer R.J., Ferro R.S.T., Tokay T., 2001, Modelling the size selectivities of a trawl codend and an associated square mesh panel. ICES J. Mar. Sci. 58, 657-671. 